\title{
HUBUNGAN ANTARA KOORDINASI MATA TANGAN, POWER OTOT LENGAN DAN KEKUATAN OTOT PERUT DENGAN KEMAMPUAN PUKULAN SMASH DALAM PERMAINAN BULUTANGKIS
}

\author{
Ghon Lisdiantoro \\ ghontaro@gmail.com \\ IKIP PGRI MADIUN
}

\begin{abstract}
ABSTRACK
This study has a purpose to determine the relationship between each variable. This study used descriptive correlational study. The study population was students of IKIP PGRI MADIUN in total 60 students. The research sample was 30 male students with techniques purposive sampling. This research resulted in the following conclusions: (1) there is a significant correlation between hand-eye coordination with the ability to smash, the correlation coefficient of 0.550 . With $\mathrm{N}=30,5 \%$ value rtabel 0463 . Turns rhitung $=0.550>5 \%$ rtabel 0463 . (2) there is a significant correlation between muscle power arm with the ability to smash, the correlation coefficient of 0.651 . With $\mathrm{N}=30,5 \%$ value rtabel 0463 . Turns $\mathrm{r}$ hitung $=0651>\mathrm{r}$ tabel $5 \% 0463(3)$ there is a significant correlation between the strength of the abdominal muscles with the ability to smash, the correlation coefficient of 0.549 . With $\mathrm{N}=30,5 \%$ value $\mathrm{r}$ tabel 0463 . Turns $\mathrm{r}$ hitung $=0549>5 \% \mathrm{r}$ tabel 0463. (4) there is a significant correlation between hand-eye coordination, power arm muscles and abdominal muscle strength with the ability to smash, Retrieved of 12,581 correlation coefficient, with $\mathrm{F}$ table $\mathrm{db}=3$ opponents 26 with a significance level of $5 \%=4.64$ turns $\mathrm{F}$ regresi price $=12.581>$ prices $\mathrm{F}$ tabel $5 \%=4.64$.
\end{abstract}

\begin{abstract}
Abstrak
Penelitian ini bertujuan untuk mengetahui hubungan antara masing- masing variabel. Penelitian ini menggunakan metode deskriptif dengan studi korelasional. Populasi penelitian adalah pada mahasiswa putra peserta pembinaan prestasi IKIP PGRI MADIUN yang berjumlah 60 mahasiswa. Sampel penelitian sebanyak 30 mahasiswa putra dengan teknik purpusive sampling. Penelitian ini menghasilkan simpulan sebagai berikut: (1) terdapat hubungan yang signifikan antara koordinasi mata tangan dengan kemampuan smash, diperoleh koefisien korelasi sebesar 0.550. Dengan $N=30$, nilai $r_{\text {tabel }} \%$ 0.463. Ternyata $r_{\text {hitung }}=0.550>r_{\text {tabel }} \% 0.463$. (2) terdapat hubungan yang signifikan antara power otot lengan dengan kemampuan smash, diperoleh koefisien korelasi sebesar 0.651 . Dengan $\mathrm{N}=30$ nilai $r_{\text {tabel } 5 \%} 0.463$. Ternyata $r_{\text {hitung }}=0.651>r_{\text {tabel }}$ 5\% 0.463 (3) terdapat hubungan yang signifikan antara kekuatan otot perut dengan kemampuan smash, diperoleh koefisien korelasi sebesar 0.549 . Dengan $\mathrm{N}=30$, nilai $\mathrm{r}_{\text {tabel }} \% 0.463$. Ternyata $\mathrm{r}_{\text {hitung }}=0.549>\mathrm{r}_{\text {tabel }} 5 \%$ 0.463. (4) terdapat hubungan yang signifikansi antara koordinasi mata tangan, power otot lengan dan kekuatan otot perut dengan kemampuan smash, Diperoleh koefisien korelasi sebesar12,581, dengan $\mathrm{F}_{\text {tabel }}$ dengan $\mathrm{db}=3$ lawan 26 dengan taraf signifikansi $5 \%=4.64$ ternyata harga $F_{\text {regresi }}=12,581>$ harga $F_{\text {tabel } 5 \%}=4.64$.
\end{abstract}




\section{A. PENDAHULUAN}

Olahraga merupakan kegiatan yang banyak manfaatnya bagi manusia. Oleh karenanya makin banyak orang yang gemar melakukan olahraga, karena merupakan salah satu cabang olahraga permainan yang banyak digemari oleh masyarakat Indonesia adalah bulutangkis. Dalam melakukan permainan bulutangkis ada yang bertujuan hanya sekedar untuk rekreasi dan ada juga yang untuk berprestasi.

Prestasi yang tinggi dalam olahraga, khususnya pada permainan bulutangkis tidak dapat diraih dengan mudah, tetapi diperlukan usaha yang keras dan tidak mengenal lelah. Prestasi bulutangkis dapat ditingkatkan dan dipertahankan melalui perbaikan kualitas sistem pembinaan dan pelatihan yang dilakukan. Ada beberapa faktor yang mempengaruhi pencapaian prestasi olahraga, khususnya bulutangkis. Untuk mencapai prestasi yang setinggi-tingginya khususnya pada permainan bulutangkis dibutuhkan empat aspek latihan yang harus dimiliki oleh tiap atlet, yaitu aspek fisik, teknik, taktik dan mental (kematangan juara). Keempat aspek itu harus dikembangkan melalui latihan.

Latihan dasar dalam permainan bulutangkis yang perlu dikuasai oleh setiap pemain ada bermacam-macam. Dalam permainan bulutangkis diperlukan kecakapan dasar atau teknik dasar bermain bulutangkis. Dengan menguasai kecakapan dasar yang ada, maka seorang pemain akan dapat melakukan suatu permainan dengan baik.

Teknik yang paling utama yang harus dikuasai oleh pemain bulutangkis diantaranya pukulan servis, lob, dropshot, drive dan smash. Salah satu unsur teknik dasar yang sangat penting dalam bulutangkis adalah pukulan smash. Teknik dasar pukulan smash harus dikuasai oleh setiap pemain bulutangkis.

Pukulan smash yang keras dan cepat sangat efektif untuk mematikan lawan. Untuk dapat menghasilkan pukulan smash yang keras dan cepat sangat diperlukan power atau daya ledak otot, terutama kekuatan otot utama yang terlibat gerakan pukulan smash. 
Sehubungan dengan itulah, maka akan diadakan penelitian tentang 'Hubungan antara koordinasi mata tangan, power otot lengan dan kekuatan otot perut terhadap kemampuan pukulan smash dalam permainan bulutangkis pada mahasiswa putra peserta pembinaan prestasi Institut Keguruan Ilmu Pendidikan PGRI MADIUN.

Mengacu pada pokok - pokok masalah yang dirumuskan pada pembatasan masalah tersebut diatas, maka masalah - masalah yang akan dibahas dapat dirumuskan sebagai berikut :

1. Adakah hubungan antara koordinasi mata tangan dengan kemampuan smash bulutangkis pada mahasiswa putra peserta pembinaan prestasi IKIP PGRI MADIUN.

2. Adakah hubungan antara power otot lengan dengan kemampuan smash bulutangkis pada mahasiswa putra peserta pembinaan prestasi IKIP PGRI MADIUN.

3. Adakah hubungan antara kekuatan otot perut dengan kemampuan smash bulutangkis pada mahasiswa putra peserta pembinaan prestasi IKIP PGRI MADIUN.

4. Adakah hubungan antara koordinasi mata tangan, power otot lengan dan kekuatan otot perut dengan kemampuan smash bulutangkis pada mahasiswa putra peserta pembinaan prestasi IKIP PGRI MADIUN.

\section{B. METODE PENELITIAN}

Tempat penelitian sekaligus sebagai tempat pengambilan data penelitian. Tempat penelitian dilaksanakan di lapangan bulu tangkis IKIP PGRI MADIUN. Waktu penelitian atau pengambilan data penelitian dilaksanakan pada pagi hari mulai pukul 07.00 sampai selesai.

Metode yang digunakan dalam penelitian ini adalah metode deskriptif dengan studi korelasional. Metode diskriptif adalah suatu penelitian yang bertujuan untuk mendapatkan informasi mengenai fenomena atau situasi yang aktual atau situasi yang ada pada saat penelitian berlangsung. Sugiyanto (1993:52), menyatakan bahwa, jenis penelitian yang dapat digolongkan atau diklasifikasikan 
sebagai penelitian deskriptif adalah survei, studi kasus, studi perkembangan, studi follow-up, analisis dokumenter, studi arah dan studi korelasional.

Studi korelasional digunakan untuk menguji hipotesis yang telah dirumuskan sebelumnya. Dalam hipotesis dinyatakan bahwa ada sumbangan antara satu variabel dengan variabel yang lain, maka prosedur korelasional dapat digunakan untuk menguji hipotesis tersebut. Sugiyanto (1993:52), menyatakan bahwa :

Populasi adalah sejumlah individu yang akan dijadikan obyek penelitian dan keseluruhan dari individu-individu tersebut paling sedikit mempunyai satu sifat yang sama. Populasi menurut Sutrisno Hadi (1987:220), adalah "Seluruh penduduk yang dimaksudkan untuk diselidiki. Bahwa populasi itu dibatasi dengan sejumlah penduduk dan paling sedikit mempunyai satu sifat yang sama"..

Alasan penelitian mengambil populasi berdasarkan kriteria-kriteria atau persyaratan sebagai berikut :

1. Mereka berjenis kelamin sama, yaitu pemain putra.
2. Mereka sama-sama mahasiswa putra peserta pembina prestasi Universitas Tunas Pembangunan Surakarta yang sedang meningkatkan kemampuan dan ketrampilan gerak.

3. Mereka sama-sama sedang melakukan latihan pukulan smash. Mengacu pada alasan-alasan tersebut diatas, maka kriteria populasi yang diambil untuk obyek penelitian telah memenuhi syarat sebagai populasi, dimana persyaratan populasi minimal memiliki satu sifat yang sama, sehingga seluruh mahasiswa putra peserta pembinaan prestasi IKIP PGRI MADIUN dapat dijadikan populasi penelitian.

Karena jumlah populasinya adalah 60 Orang sementara menurut (Sutrisno Hadi, 1975:22), bahwa penelitian itu harus mempertimbangkan tenaga, biaya, waktu, bertolak dari pendapat tersebut maka populasi tidak digunakan seluruhnya, namun menggunakan sejumlah sampel.

Dalam penelitian ini sampel diartikan sebagai suatu bagian atau wakil dari populasi yang diteliti dan dapat mewakili seluruh populasi. 
Teknik pengambilannya dengan Purpusive sampling atau sampling bertujuan, adalah sebuah teknik pengambilan sampel yang ciri atau karakteristiknya sudah diketahui lebih dulu berdasarkan ciri atau sifat populasi. Kriteria sampel ditentukan oleh si peneliti itu sendiri sesuai dengan tujuan penelitian.Karena itu Purpusive Sampling acak sekali disebut juga judgement sampling maka sampel yang diambil khusus.

Mengenai besarnya sampel tidak ada ketentuan yang baku. Secara statistik memang ada prosedur yang memperkirakan besarnya sampel yang diperlukan yang memerlukan variansi populasi secara tepat yang sering kali sulit diketahui secara pasti. Yang penting untuk lebih diperhatikan adalah respresentatifnya sampel penelitian yang digunakan. Berdasarkan pada pedoman penentuan jumlah sampel tersebut, karena jumlah populasinya 60 mahasiswa, maka dari populasi tersebut diambil 30 mahasiswa putra yang terbaik. Sampel yang digunakan dalam penelitian ini adalah mahasiswa putra yang dipilih dalam pembinaan prestasi IKIP PGRI MADIUN.
Teknik pengumpulan data dalam penelitian ini dengan mengadakan pengetesan pada sampel percobaan. Alat untuk mengukur disebut sebagai instrumen penelitian. Instrumen penelitian digunakan bertujuan untuk mengukur atau menangkap gejalagejala dan sifat-sifat variabel yang diteliti. Ada gejala atau sifat variabel yang dapat secara langsung diukur, tetapi ada yang tidak dapat diukur secara langsung. Teknik pengumpulan data dalam penelitian ini dengan mengadakan pengetesan pada sampel percobaan. Alat untuk mengukur disebut sebagai instrumen penelitian. Adapun pelaksanaan test dapat diuraikan sebagai berikut :

1. Tes koordinasi mata tangan Koordinasi mata-tangan dilakukan dengan tes memantulkan bola ke tembok

2. Tes power otot lengan dengan melempar medicine ball put

Tes dan pengukuran olahraga (Ismaryati, 2009:64-65)

3. Tes kekuatan otot perut dengan situp

Tes dan pengukuran olahraga (Ismaryati, 2009:119-120) 
4. Tes kemampuan pukulan smash bulutangkis

Kemampuan pukulan smash bulutangkis diambil dengan tes ketepatan smash dari

Analisis data merupakan langkah penting dalam penelitian. Secara garis besar, pekerjaan analisis data meliputi 3 langkah, yaitu : persiapan, tabulasi dan penerapan data sesuai dengan pendekatan penelitian.

Berdasarkan pada data hasil tes koordinasi mata-tangan,power otot lengan, kekuatan otot perut tes smash diperoleh data yang disampaikan dalam bentuk tabel sebagai berikut :

Tabel 1. Data Hasil Tes Koordinasi Mata-Tangan,Power Otot Lengan, Kekuatan Otot Perut Tes Smash

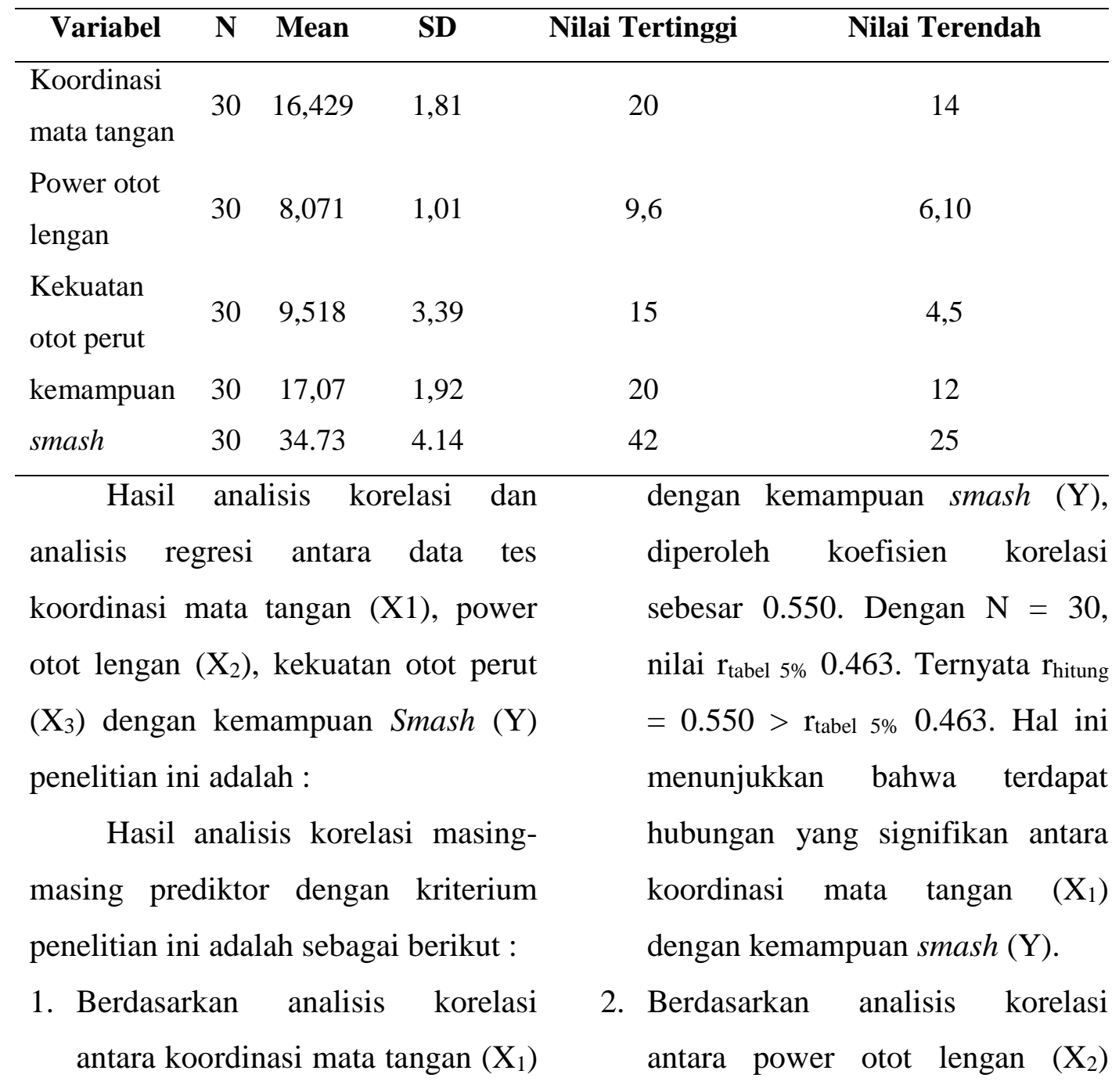


Ghon Lisdiantoro: Hubungan Antara Koordinasi Mata ... |216

dengan kemampuan smash (Y), diperoleh koefisien korelasi sebesar 0.651. Dengan $\mathrm{N}=30$ nilai $\mathrm{r}_{\text {tabel }} 5 \%$ 0.463. Ternyata $\mathrm{r}_{\text {hitung }}=$ $0.651>\mathrm{r}_{\text {tabel }} 5 \%$ 0.463. Hal ini menunjukkan bahwa terdapat hubungan yang signifikan antara power otot lengan $\left(\mathrm{X}_{2}\right)$ dengan kemampuan smash (Y).

3. Berdasarkan analisis korelasi antara kekuatan otot peru $\left(\mathrm{X}_{3}\right)$ dengan kemampuan smash (Y), diperoleh koefisien korelasi sebesar 0.549. Dengan $\mathrm{N}=30$, nilai $r_{\text {tabel }} \% 0.463$. Ternyata $r_{\text {hitung }}$ $=0.549>\mathrm{r}_{\text {tabel }} 5 \%$ 0.463. Hal ini menunjukkan bahwa terdapat hubungan yang signifikan antara kekuatan otot perut $\left(\mathrm{X}_{3}\right)$ dengan kemampuan smash (Y).

Analisis regresi yang dilakukan dalam penelitian ini menggunakan analisis regresi ganda tiga prediktor. Hasil analisis regresi antara data tes koordinasi mata tangan $\left(\mathrm{X}_{1}\right)$, power otot lengan $\left(\mathrm{X}_{2}\right)$, kekuatan otot perut $\left(\mathrm{X}_{3}\right)$ dengan kemampuan smash (Y) dalam penelitian ini adalah sebagai berikut

1. Persamaan garis regresinya adalah
$Y=0,404+0,355 X_{1}+0,742 X_{2}+$ $0,168 X_{3}$

2. Koefisien korelasi dan determinasi prediktor dan kriterium

$$
\begin{array}{ll}
\mathrm{R}_{\mathrm{y}(1,2,3)}=0.912 \\
\mathrm{R}_{\mathrm{y}(1,2,3)}^{2}=0.772
\end{array}
$$

3. Uji signifikansi analisis regresi

Dari hasil analisis regresi tersebut dapat disimpulkan, dengan $\mathrm{db}=\mathrm{m}$ lawan $\mathrm{N}-\mathrm{m}-1=3$ lawan 26, harga $\mathrm{F}_{\text {tabel }}$ 5\% adalah 4.64. Sedangkan nilai $F$ yang diperoleh adalah 12.821 ternyata lebih besar dari angka batas penolakan hipotesa nol. Dengan demikian hipotesa nol ditolak, yang berarti bahwa terdapat hubungan yang signifikan antara koordinasi mata tangan $\left(\mathrm{X}_{1}\right)$, power otot lengan $\left(\mathrm{X}_{2}\right)$, kekuatan otot perut $\left(\mathrm{X}_{3}\right)$ dengan kemampuan smash (Y). Adapun besarnya nilai $\mathrm{R}^{2}$ antara koordinasi mata tangan $\left(\mathrm{X}_{1}\right)$, power otot lengan $\left(\mathrm{X}_{2}\right)$, kekuatan otot perut $\left(\mathrm{X}_{3}\right)$ dengan kemampuan smash (Y) adalah 0.772 . 
217 | Premiere Educandum, Volume 6 Nomor 2, Desember 2016, 210 - 221

\section{HASIL PENELITIAN DAN PEMBAHASAN}

Berdasarkan hasil analisis data yang dilakukan, maka dapat disampaikan hal-hal sebagai berikut :

Ada hubungan yang signifikan antara koordinasi mata tangan dengan kemampuan pukulan smash pada mahasiswa putra pembinaan prestasi IKIP PGRI MADIUN. $\left(\mathrm{rx}_{1} \mathrm{y}=0,550>\right.$ $\left.\mathrm{r}_{\text {tabel } 1 \%}=0,463\right)$. Berdasarkan hasil analisis data variabel bebas koordinasi mata tangan dengan kemampuan pukulan smash ternyata hasilnya lebih besar dari harga $r_{\text {tabel, }}$ sehingga hipotesis yang menyatakan bahwa, "Ada hubungan yang signifikan antara koordinasi mata tangan dengan kemampuan pukulan smash pada mahasiswa putra pembinaan prestasi IKIP PGRI MADIUN" diterima kebenarannya. Variabel koordinasi mata tangan memberikan korelasi yang menyakinkan terhadap peningkatan keterampilan smash. Untuk itu dalam rangka peningkatan kemampuan smash seorang pemainbulutangkis harus mampu mengintegrasikan gerakan - gerakan pukulan smash kedalam gerakan yang utuh dan selaras. Kualitas koordinasi mata tangan yang dimiliki oleh seorang pemain berpengaruh dalam melakukan pukulan smash

Dengan kemampuan pukulan smash pada mahasiswa putra pembinaan prestasi IKIP PGRI MADIUN. $\left(\mathrm{rx}_{1} \mathrm{y}=0,651>\mathrm{r}_{\text {tabel }} 5 \%=\right.$ 0,463). Berdasarkan hasil analisis data variabel bebas power otot lengan dengan kemampuan pukulan smash. ternyata hasilnya lebih besar daripada harga $r_{\text {tabel}}$, sehingga hipotesis yang menyatakan bahwa, "Ada hubungan yang signifikan antara power otot lengan dengan kemampuan pukulan smash pada mahasiswa putra pembinaan prestasi IKIP PGRI MADIUN. Untuk menghasilkan pukulan smash yang baik sangat diperlukan power otot lengan.daya ledak otot lengan sangat besar peranannya dalam menghasilkan pukulan smash yang baik.

Ada hubungan yang signifikan kekuatan otot perut dengan kemampuan pukulan smash pada mahasiswa putra pembinaan prestasi IKIP PGRI MADIUN $\left(\mathrm{rx}_{1} \mathrm{y}=0.561>\right.$ $\left.\mathrm{r}_{\text {tabel }} 5 \%=0,463\right)$. Berdasarkan hasil analisis data variabel bebas kekuatan otot perut dengan kemampuan pukulan smash. ternyata hasilnya lebih 
besar daripada harga $r_{\text {tabel, }}$, sehingga hipotesis yang menyatakan bahwa, "Ada hubungan yang signifikan antara kekuatan otot perut dengan kemampuan pukulan smash pada mahasiswa putra pembinaan prestasi IKIP PGRI MADIUN." diterima kebenarannya. Hal ini cukup beralasan, karena kekuatan otot perut sangat berperan dalam pukulan smash bulutangkis pada saat hendaak memukul lengan diayunkan dari belakang kemudian ke depan otot perut berkontraksi sehingga apat menghasilkan pukulan smash yang meyakinkan.

Ada hubungan yang meyakinkan antara koordinasi mata tangan, power otot lengan dan kekuatan otot perut dengan kemampuan pukulan smash pada mahasiswa putra pembinaan prestasi universitas tunas pembangunan surakarta tahun 2013. $\left(\mathrm{F}_{\text {regresi }}=12,851>\mathrm{F}_{\text {tabel } 1 \%}=4.64\right)$. Berdasarkan hasil analisis data didapat harga $F_{\text {hitung }}$ lebih besar daripada harga $\mathrm{F}_{\text {tabel, }}$ sehingga hipotesis yang menyatakan bahwa, "Ada hubungan yang signifikan antara koordinasi mata tangan, power otot lengan dan kekuatan otot perut dengan kemampuan pukulan smash pada mahasiswa putra pembinaan prestasi IKIP PGRI MADIUN.” diterima kebenarannya, baik secara sendirisendiri maupun secara bersama-sama. Ketiga prediktor memberikan korelasi yang signifikan dengan keterampilan smash. Selain ketiga variabel tersebut, banyak sekali faktor-faktor yang dapat mendukung keberhasilan siswa didalam meningkatkan keterampilan melakukan smash. Faktor-faktor lain tersebut berkenaan dengan kondisi fisik, proporsi tubuh, penguasaan teknik dasar menembak maupun faktor-faktor lain baik yang berasal dari dalam maupun dari luar. Disamping itu kemampuan individu dan bakat akan dapat mempengaruhi hasil.

\section{SIMPULAN DAN SARAN}

Berdasarkan pada uraian pembahasan permasalahan di atas serta hasil pembahasan analisis data penelitian, maka secara empirik dapat disampaikan hal-hal sebagai berikut:

1. Ada hubungan yang signifikan antara koordinsi mata tangan $\left(\mathrm{X}_{1}\right)$ dengan kemampuan pukulan smash (Y). Hal ini dapat dibuktikan dengan perolehan harga 
koefisien prediktor koordinasi mata tangan sebesar 0.550. Setelah dikonsultasikan dengan harga $r_{\text {tabel }}$ dengan $\mathrm{N}=30$ dengan taraf signifikansi $5 \%=0,463$ ternyata harga $\mathrm{rx}_{1} \mathrm{y}=0,550>$ harga $\mathrm{r}_{\text {tabel }} \%$ $=0,463$.

2. Ada hubungan yang signifikan antara power otot lengan $\left(\mathrm{X}_{2}\right)$ dengan kemampuan pukulan smash (Y). Hal ini dapat dibuktikan dengan perolehan harga koefisien prediktork power otot lengan sebesar 0.651. Setelah dikonsultasikan dengan harga $r_{\text {tabel }}$ dengan $\mathrm{N}=30$ dengan taraf signifikansi $5 \%=0,463$ ternyata harga $\mathrm{rx}_{1} \mathrm{y}=0,550>$ harga $\mathrm{r}_{\text {tabel }} \%$ $=0,463$.

3. Ada hubungan yang signifikan antara kekuatan otot perut $\left(\mathrm{X}_{3}\right)$ dengan kemampuan pukulan smash (Y). Hal ini dapat dibuktikan dengan perolehan harga koefisien prediktor kekuatan otot perut sebesar 0,549. Setelah dikonsultasikan dengan harga $r_{\text {tabel }}$ dengan $\mathrm{N}=30$ dengan taraf signifikansi $5 \%=0,463$ ternyata harga $\operatorname{rx}_{1} \mathrm{y} 0,549>$ harga $r_{\text {tabel }} 5 \%=$ 0,463 .
4. Ada hubungan yang meyakinkan antara koordinasi mata tangan, power otot lengan dan kekuatan otot perut dengan keterampilan smass (Y). Hal ini dapat dibuktikan dengan perolehan harga koefisien korelasi ganda $F_{\text {regresi }}$ sebesar 12,851, setelah dikonsultasikan dengan harga $\mathrm{F}_{\text {tabel }}$ dengan $\mathrm{db}=3$ lawan 26 dengan taraf signifikansi $5 \%=4.64$ ternyata harga $F_{\text {regrei }}=12,851>$ harga $\mathrm{F}_{\text {tabel 5\% }}=4.64$.

Berdasarkan pada hasil penelitian dan simpulan yang telah disebutkan di atas, timbul beberapa wawasan atau pandangan yang dikemukakan oleh peneliti yang berupa saran-saran sebagai berikut :

1. Sehubungan variabel koordinasi mata tangan, power otot lengan dan persepsi kinestetik ada hubungan yang meyakinkan dengan keterampilan smash, maka bagi pelatih dan guru pendidikan jasmani agar dapat memanfaatkan koordinasi mata tangan dan selalu melatih power otot lengan dan kekuatan otot perut secara intensif, teratur dan sistematis kepada siswa, agar dengan 
pembelajaran yang diberikan akan lebih mengoptimalkan kemampuan anak didik di dalam melakukan smash.

2. Bagi para pembina, pelatih dan guru pendidikan jasmani, agar hasil penelitian ini dapat digunakan sebagai dasar pemikiran dalam rangka membina dan metatih para siswanya untuk melakukan latihan dengan menekankan pada pemanfaatan power otot lengan dan peningkatan kekuatan otot perut serta pemanfaatan panjang lengan, agar dengan peningkatan itu para siswa dapat melakukan smash dengan kualitas yang lebih baik. Bahkan dalam rangka seleksi atau pemilihan bibit pemain bulutangkis dapat dilakukan melalui seleksi siswa dengan pengetesan koordinasi mata tangan, tes power otot lengan dan kekuatan otot perut pada siswa yang bersangkutan.

3. Mengingat penelitian ini dilakukan hanya dalam lingkup yang sempit, untuk lebih baiknya perlu diadakan penelitian ulang dengan cakupan populasi yang lebih luas, sampel lebih banyak, variabel ditambah ataupun jika diperlukan variabel dapat diganti dan dikombinasikan dengan variabel yang lain yang sesuai.

\section{DAFTAR RUJUKAN}

Bompa, T. O. 1990. Theory and Methodology of Training. Kendall/Hant : IOWA of University

Harsono. 1988. Coaching dan Aspekaspek Psikologi dalam Coaching. Jakarta:

PT. DirjenDikti P2LPT.

Ismaryati. 2009. Tes Dan Pengukuran Olahraga. Surakarta: LPP UNS dan UNS.

M. Sajoto. 1995. Pembinaan Kondisi Fisik dalam Olahraga. Semarang: IKIP Semarang Press.

M. Sajoto. 1988. Pembinaan Kondisi Fisik. Jakarta: Depdikbud.

Radcliffe James C. \& Farentinos Robert C. 1985. Pliometrik untuk Meningkatkan Power. Alih bahasa. M. Furqon h. \& Muchsin Doewes. Surakarta: Program Studi Ilmu Keolahragaan Program Pasca Sarjana Universitas Sebelas Maret.

Rusli Lutan. 1992. Dasar-dasar Kepelatihan. Depdikbud.

Saiful Arisanto. 1990. Pola Dasar Pembinaan Bulutangkis. Kudus : PB Timas Much Kalisari Cilongok. Djarum Kudus. 
Sudjarwo. 1993. Ilmu Kepelatihan I. Surakarta: UNS Press

Sugiyanto. 1993. Perkembangan dan BelajarMotorik. Jakarta: Depdikbud. Direktorat Jenderal Pendidikan Dasar dan Menengah Bagian Proyek Peningkatan Mutu Guru Penjaskes. SD Setra D-II.

Suharno H.P. 1993. Ilmu Coaching Umum. FPOK IKIP: Jogjakarta.

Sutrisno Hadi. 1987. Analisis Regresi. Yogyakarta. Andi Offset.

Tohar. 1992. Olahraga Pilihan Bulutangkis. Jakarta:
Departemen Pendidikan dan Kebudayaan, Direktorat Jenderal Pendidikan Dasar dan Menengah, Direktorat Pendidikan Guru dan Tenaga Teknis Bagian Proyek Peningkatan Muhi Guru Pendidikan Jasmani dan Kesehatan.

Yusuf Hadisasmita \& Aip Syarifuddin. 1996. Ilmu Kepelatihan Dasar. Jakarta: Departemen Pendidikan dan Kebudayaan. Direktorat Jendral Pendidikan Tinggi. Proyek Pendidikan Tenaga Akademik. 